\section{A New Electrical Contact Alloy With High Reliability Based on Gold}

\author{
Yuantao Ning, Ying Peng, Hong Dai \\ Kunming Institute of Precious Metals, \\ Kunming 650221, Yunnan, China \\ E-mail: ytning2002@yahoo.com.cn
}

\section{Received 13 April 2002}

A new gold alloy (NSCCA) was designed and prepared for light duty precision contacts. The microstructure, mechanical, electrical and applied properties of the NSCGA alloy were studied. The NSCGA alloy contains copper, palladium, platinum, nickel and rhodium as well as gold. The unique structure comprised of two phases, a gold-rich solid solution as the matrix and a platinum-rich solid solution as a strengthening phase. The matrix presents short-range ordering in the temperature range $200-900^{\circ} \mathrm{C}$, which leads to the specific resistance of the alloy decreasing, and a modulated structure at low temperatures, which is responsible for age strengthening. The NSCGA alloy has low specific resistance, high tensile strength and high Vickers hardness. Various TO- 5 type relays (TO- 5 relay is a sealed mini relay with magnetic preservation) with NSCGA alloy as contacts were prepared and tested in a special relay factory under industrial conditions. NSCGA alloy contacts showed stable and low contact resistance, long loading life and high reliability, superior to that of an available conventional sixcomponent palladium alloy. The NSCGA alloy and the composites with NSCGA alloy as a covering layer and copper alloys as a base have been evaluated in various TO-5 type mini relays and other electric products.

\section{Design of New Gold Alloy}

Electric contact materials are essential electronic components in electronic products. Reliability is the most important performance characteristic for light duty electric contact materials used in mini relays. In addition to high electrical and thermal conductivity, gold has high chemical stability and does not form surface films of oxide, sulfide and 'brown powder' in oxygen-, sulfur- and organic vaporcontaining atmospheres, so maintains low and stable contact resistance. Gold is suitable for applications in light duty precision contacts, and is rarely replaced by other metals or alloys under the condition of the power distribution with very

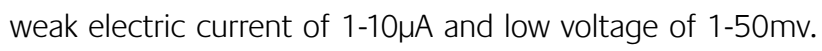
On the other hand, however, gold contacts are liable to arc and form sharp splinters and even to weld, due to its low yield strength, elasticity and melting point as well as its voltampere characteristic. Therefore the alloying of gold is necessary to enhance the above properties.

Multi-component alloying has been a main trend for the development of electric contact alloys since the 1970s. In the 1980s, the price of gold was ca. 3-4 times higher than that of palladium. As a results of this a series of multi-component palladium alloys were studied and used as contact materials in weak electric current and light load field. Among them, a palladium alloy, composition Pd-30 Ag-14 Cu-10 Pt-10 Au-1 Zn (wt.\%) [1-3], had more extensive applications and was also used in mini relays. Electrical contact materials made of palladium alloys, however, are often unable to satisfy the demand for low electric current level and high reliability due to the formation of insulating polymers from organic vapors. On the other hand, the price of palladium fluctuates rapidly and has been much higher than that of gold in recent years. To satisfy the demand for an electrical contact material with higher reliability and lower price, a new electrical contact alloy with high reliability based on gold was studied in the present work.

The design of the compositions of the new gold alloy reflected two principles. At first, it should be a multicomponent alloy based on gold in order to ensure high reliability and good comprehensive properties. Secondly, it must have high hardness and strength by means of second phase strengthening in order to have high wear resistance and long duration of service. More specifically, the alloy is sixcomponent, composed of gold, copper, palladium, platinum, nickel and rhodium. The content of gold of a typical alloy is equal to 61 wt.\%, and that of copper, palladium and platinum is 14,10 , and 10 percent in weight, respectively, in addition to small amounts (5 wt.\%) of nickel and rhodium. Because the solubility of rhodium in gold is negligible [4], rhodium must be alloyed to platinum to form a second phase. The alloy is a new six-component gold alloy 


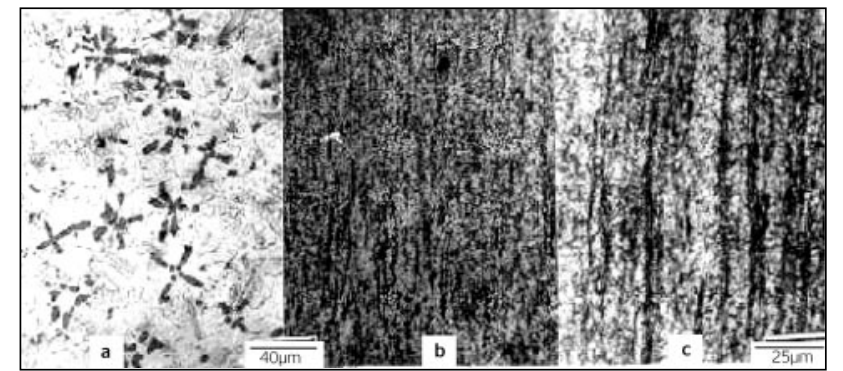

Figure 1

Low magnification metallographs of NSCGA alloy: (a) as cast, (b, c) alloy cold deformed and followed by annealing at $500^{\circ} \mathrm{C}$ (b) and $700^{\circ} \mathrm{C}$ (c) for $0.5 \mathrm{~h}$

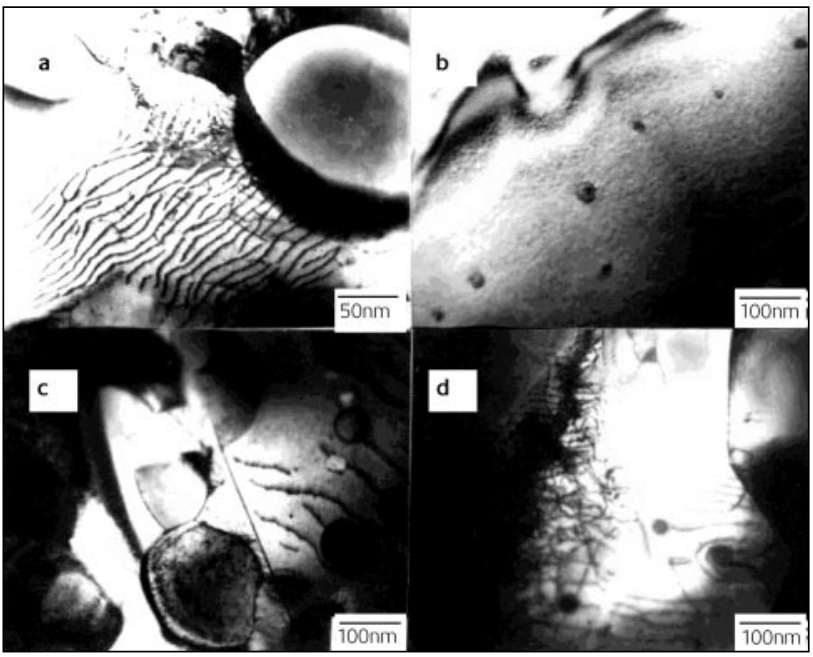

Figure 2

TEM photos of NSCCA alloy at different states: (a) annealed at $1050^{\circ} \mathrm{C}$ (b) annealed at $800^{\circ} \mathrm{C}$ after cold deformation; (c) aged at $350^{\circ} \mathrm{C}$ and (d) aged at $200^{\circ} \mathrm{C}$

corresponding to the Pd-30Ag-14Cu-10Pt-10Au-1Zn sixcomponent palladium alloy and was designated NSCGA. In order to compare the physical properties, especially the applied performance in electrical contacts, an available sixcomponent palladium alloy with compositions of Pd-30Ag14Cu-10Pt-10Au-1Zn [5], which was named SCPA, was used as a reference alloy. SCPA is a well-known contact alloy in sliding contacts and also in contacts and spring leaves in TO-5 type mini-relays.

\section{Microstructure of NSCGA Alloy}

The low magnification metallographs shown in Figure 1 showed two phases in casting and the cold deformed NSCCA alloy. The second phase in the casting alloy appeared as an irregular petal dendrite form. During cold deformation, the second phase was extended along the rolling, (drawing), direction and formed a fibre texture. Although the cold deformed matrix phase showed obvious recovery and recrystallisation after annealing at $500^{\circ} \mathrm{C}$ and $700^{\circ} \mathrm{C}$ for $0.5 \mathrm{~h}$, the second phase still presented as a fibre texture because it has higher melting and recrystallisation temperatures than the matrix phase.

TEM photos (Figure 2) showed the microstructure of NSCGA alloy annealed at high temperature and aged at low temperature. At high temperature of $1050^{\circ} \mathrm{C}$, which is close to the melting temperature $\left(1090^{\circ} \mathrm{C}\right)$ of the matrix, the alloy is still two-phase and the matrix phase presented a layered structure. The results indicated that the layered matrix structure and second phase were not precipitates but formed through crystallisation. The matrix phase of the alloy annealed at $850^{\circ} \mathrm{C}$ maintained the structure characteristic at high temperatures. Cold deformation made the grains of the second phase distribute along lines. Figure $2 \mathrm{~b}$ shows the distribution of the second phase in the alloy annealed at $800^{\circ} \mathrm{C}$ after cold deformation. The alloy aged at low temperatures was still a two-phase structure made of layer a matrix and granulated second phase (Figure 2c, 2d).

The spacing $(\mathrm{L})$ between layers of the matrix for the alloy quenched from $800^{\circ} \mathrm{C}$ is about $0.373 \mathrm{~nm}$. The smoothgranulated second phase, less than $100 \mathrm{~nm}$ in length was distributed in the layered structure and after aging also on twins, grain boundaries and dislocation lines (Figure 2c, 2d).

The X-ray diffraction patterns of NSCGA alloy annealed at high temperatures and aged at low temperatures presented a two-phase structure as shown in Figure 4. For the alloy annealed at $850^{\circ} \mathrm{C}$, the matrix phase is a face-centered cubic (fCc) solid solution with lattice parameter $\mathrm{a}_{1}=0.3905 \mathrm{~nm}$, and the second phase is also a fcc solid solution with lattice parameter $a_{2}=0.3775 \mathrm{~nm}$. Figure 3 showed the changes of the lattice parameters $a_{1}$ and $a_{2}$ of the matrix phase and second phase as well as spacing $(\mathrm{L})$ between layer structure of the matrix phase in the aging process. In the aging process, the changes of $a_{1}$ and $a_{2}$ values are very small,

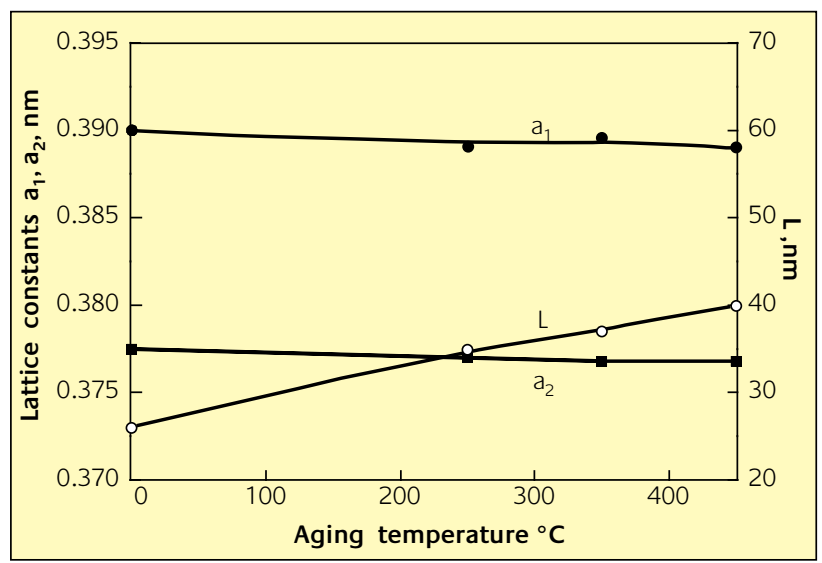

Figure 3

Changes of lattice constants of the matrix phase $\left(a_{1}\right)$ and the second phase $\left(\mathrm{a}_{2}\right)$ as well as layer spacing (L) of the layer structure of matrix phase with aging temperatures 


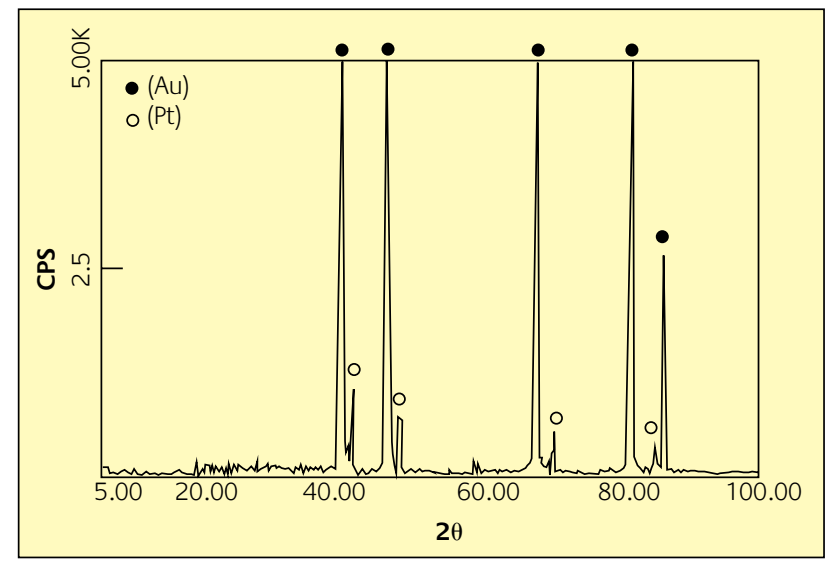

\section{Figure 4}

$X$-ray diffraction pattern of NSCGA alloy annealed at $850^{\circ} \mathrm{C}$. $(A u)=A u(C u, P d, N i)$ solid solution $(P t)=P t(A u, R h, C u, N i)$ solid solution

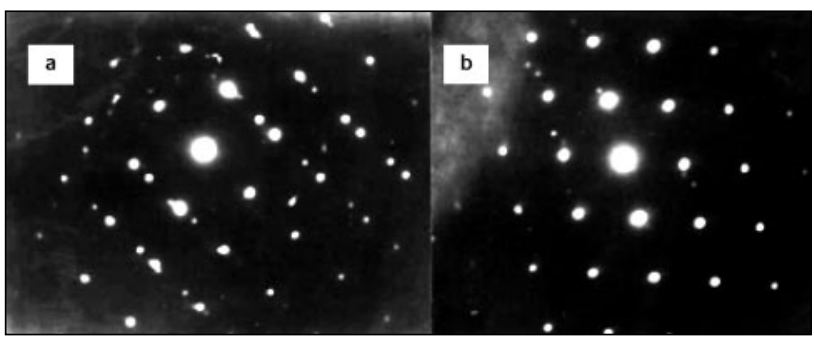

Figure 5

Electron diffraction photos of NSCCA alloy aged at $250^{\circ} \mathrm{C}(\mathrm{a})$ and annealed at $850^{\circ} \mathrm{C}($ b)

demonstrating no precipitated phase separating out, but the spacing between layers of matrix tended to increase slightly. The analytic results of an electron probe indicated that the matrix is an $\mathrm{Au}(\mathrm{Cu}, \mathrm{Pd}$, and $\mathrm{Ni}$ ) solid solution based on gold without rhodium, and the second phase is a Pt (Rh, $\mathrm{Au}, \mathrm{Cu}$, $\mathrm{Ni}$ ) solid solution based on platinum. The matrix phase did not contain rhodium, all rhodium in the alloy was present in the solid solution based on platinum. The lattice constants of the matrix and second phases were less that of gold $\left(a_{\mathrm{Au}}=0.4078 \mathrm{~nm}\right)$ and platinum ( $\left.\mathrm{apt}_{\mathrm{pt}}=0.3923 \mathrm{~nm}\right)$, respectively, because the dissolved elements in them have smaller atomic radii than gold and platinum.

A diffused diffraction peak at low angles was observed in the samples annealed at high temperature and aged at low temperature. X-ray diffraction analysis showed that shortrange order existed in the alloy with the grade of order $\sigma=0.1102$ in the annealed state at $850^{\circ} \mathrm{C}$ and $\sigma=0.1170$ for the aged state at $200^{\circ} \mathrm{C}$. The structure of the short-range order is $\mathrm{Au}_{3}(\mathrm{Cu}, \mathrm{Pd})$. Satellite spots on the (200) plane in electron diffraction pattern were observed in the alloy aged at low temperature but disappeared in the alloy annealed at $850^{\circ} \mathrm{C}$, as shown in Figure 5. It was confirmed by X-ray diffraction analysis that a modulated structure with composition modulation wavelength $\lambda \approx 9 \mathrm{~nm}$ existed in the alloy aged at low temperature, which should be related to the spinodal decomposition that occurred in Au-Ni [6] and Au-Pt [7] alloys aged at low temperatures.

\section{Physical Properties of NSCGA Alloy}

The Vickers-hardness $(\mathrm{Hv})$ and tensile strength $\left(\sigma_{\mathrm{b}}\right)$ of the annealed NSCGA alloy were $\mathrm{Hv}=222$ and $\sigma_{\mathrm{b}}=746 \mathrm{Mpa}$, respectively. The alloy has high strain hardness. The hardness increased nearly linearly with $(\varepsilon)$ compressive strain and reached $H v=310$ and $\sigma_{b}=1350 \mathrm{MPa}$ when $\varepsilon=60 \%$. The alloy is able to be age hardened to a certain extent. During the aging process, the hardness and tensile strength increased about $12 \%$ and $10 \%$, respectively. It can be seen from Figure 6 that the aging peak temperature decreases with an increase in compression strain. This is due to the increase of the stored energy of deformation. An example is given, from $350^{\circ} \mathrm{C}$ for alloy annealed at $800^{\circ} \mathrm{C}$ (curve 1 in Figure 6) to $300^{\circ} \mathrm{C}$ for alloys with $\varepsilon=60 \%$ (curve 2 in Figure 6 ) and $200^{\circ} \mathrm{C}$ for alloy with $\Psi=90 \%$ (curve 3 in Figure 6), here $\Psi$ is the shrinkage of a section of NSCGA alloy wire. A modulated structure with composition modulation occurring at low temperatures in the NSCGA alloy could be responsible for the age hardening effect.

The specific resitivity $(\rho)$ of the annealed NSCGA alloy was $31.7 \mu \Omega-\mathrm{cm}$ at room temperature. The electrical resistance measured for wire with diameter of $0.01 \mathrm{~mm}$ and length of about $1 \mathrm{~m}$ increased with rising temperature but deviated negatively from a straight line from $200^{\circ} \mathrm{C}$ to $900^{\circ} \mathrm{C}$ (Figure 7). This could be due to the short-range order effect existing in the alloy over the same temperature range, which led to the decrease of electric resistance.

The basic physical properties of NSCCA alloy are listed in

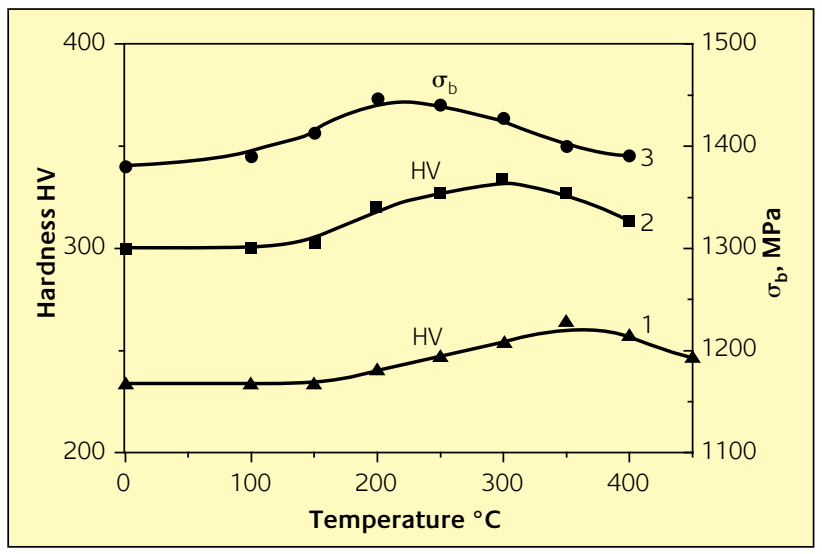

Figure 6

Changes of tensile strength $\sigma_{b}$ and Vickers Hardness Hv of NSCCA alloy with aging temperature: 1. Alloy annealed at $800^{\circ} \mathrm{C}$; 2. Cold deformation $\varepsilon=60 \%$; 3. Cold deformation $\psi=98 \%$ 


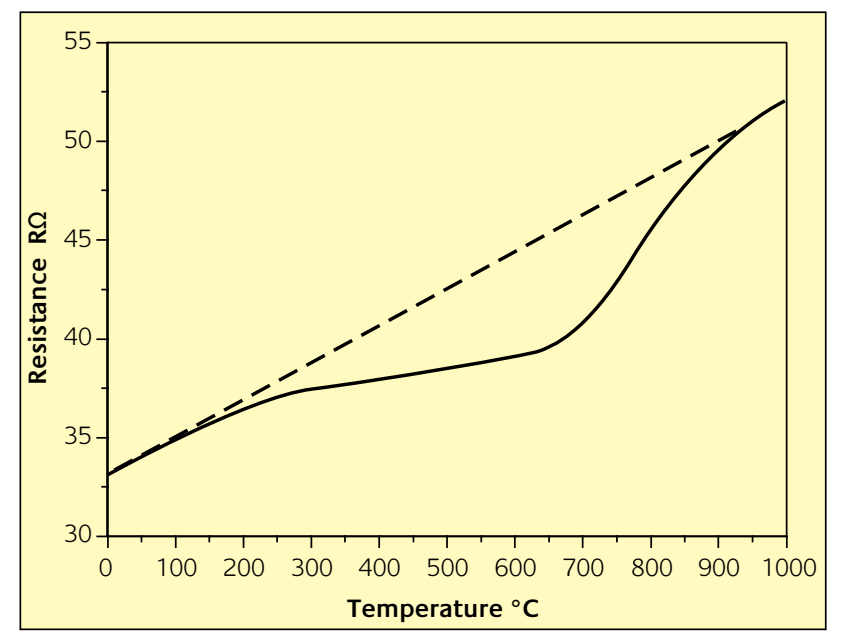

\section{Figure 7}

Changes of electric resistance of NSCCA alloy wire in the process of rising temperature

Table 1, together with the same properties of the available six-component palladium alloy (SCPA). The basic properties of both alloys are quite close.

\section{Applied Properties and Applications of NSCGA}

Using NSCGA and SCPA alloys as contacts and spring leaves, the various TO-5 type relays were prepared and tested under industrial conditions in a special relay factory. Internationally, TO-5 relay is a general term for a sealed mini relay with magnetic preservation. The experimental results were as

Table 1 Basic physical properties of NSCGA alloy

\begin{tabular}{|c|c|c|}
\hline Properties & NSCGA & SCPA [5] \\
\hline Melting point, ${ }^{\circ} \mathrm{C}$ & $1090^{*}$ & 1085 \\
\hline Density, $\mathrm{g} / \mathrm{cm}^{3}$ & 15 & 11.9 \\
\hline Specific resistance $\rho_{20^{\circ} \mathrm{C}, \mu \Omega-\mathrm{cm}}$ & 31.7 & 32 \\
\hline 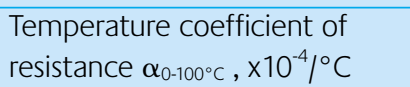 & 4.2 & 3.0 \\
\hline Modulus of elasticity E, Gpa & 113 & 110 \\
\hline \multicolumn{3}{|l|}{ Tensile strength, $\sigma_{\mathrm{b}}, \mathrm{MPa}$} \\
\hline \multirow{3}{*}{$\begin{array}{l}\text { Annealed alloy } \\
\text { Worked alloy }(\varepsilon=60 \%) \\
\text { Aged alloy }\end{array}$} & 746 & 680 \\
\hline & 1350 & 1200 \\
\hline & 1480 & 1480 \\
\hline \multicolumn{3}{|l|}{ Vickers Hardness, Hv } \\
\hline \multirow{3}{*}{$\begin{array}{l}\text { Annealed alloy } \\
\text { Worked alloy ( } \varepsilon=60 \%) \\
\text { Aged alloy }\end{array}$} & 220 & 180 \\
\hline & 310 & 280 \\
\hline & 350 & 360 \\
\hline
\end{tabular}

* Solidus melting temperature of matrix phase of NSCGA alloy, the second phase has a higher melting point follows:

\section{Contact Resistance at Low Electrical Level}

The static and dynamic contact resistances were measured for five similar TO-5 type relays at low electric level of $50 \mu \mathrm{A}$ and $30 \mathrm{mv}$ and at temperature of $85^{\circ} \mathrm{C}$ before and after running $10^{6}$ times. Here, the dynamic and static contact resistances are those measured under conditions with or without electric pressure applied on the coil with contacts. The contact resistance data measured is listed in Table 2. Relays made of NSCGA alloy as contacts and spring leaves, showed the static and dynamic contact resistances keeping stable with small values. No fault whatsoever occurred during $10^{6}$ operations. For relays made of SCPA alloy as contact and spring leaves, the static and dynamic contact resistances of 5 products before testing were higher than that of relays made of NSCGA alloy. After testing, the static contact resistance of one relay was as high as $940 \mathrm{~m} \Omega$, much larger than a specification of contact resistance $(500 \mathrm{~m} \Omega)$. Moreover, the static contact resistance of one relay and the dynamic contact resistance of another two relays with SCPA alloy contacts are infinite due to formation of PdO film on surfaces of the contacts, which lead to the electric current being turned off. The data of contact resistance measured by present work at low electric level shows that the electric contact reliability of NSCGA gold alloy is superior to that of SCPA palladium alloy.

\section{Loading Life and Climbing Limit}

The various TO- 5 types sealed mini relays with NSCGA and SCPA alloys as contacts and spring leaves were used for experiments on specified loading life and climbing limits under industrial conditions. The experimental results are listed in Table 3. In all tests, the NSCCA gold alloy showed longer life and higher reliability than the SCPA palladium alloy. In the test of loading life at ambient temperature and at the electric level of $0.5 \mathrm{~A}$ and $28 \mathrm{~V}_{D C}$, the loading life of TO-5 relays with NSCGA alloy as contacts reached above $10^{6}$ times. This was one order of magnitude higher than originally specified life of $10^{5}$ times set for TO-5 relays with SCPA alloy contacts. During the operations before $10^{5}$ times, one relay with SCPA alloy contacts was faulty 9 times. In the tests of loading life at temperatures of $85^{\circ} \mathrm{C}$ and $125^{\circ} \mathrm{C}$, the loading life and reliability of relays with NSCGA alloy contacts were significantly higher than that of relays with SCPA alloy contacts for all test conditions listed in Tables 2 and 3. For mechanical life at room temperature, the TO- 5 relays made of NSCGA alloy as contacts reached $10^{8}$ times and remained stable through various parameters and qualities, but the TO-5 relays made of SCPA alloy lost efficiency after running $10^{6}$ times. At the environment temperatures from $-65^{\circ} \mathrm{C}$ to $125^{\circ} \mathrm{C}$, the quality level of reliability of TO- 5 type mini relays with NSCGA alloy 


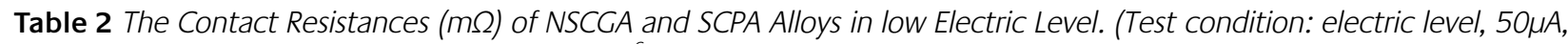
$30 \mathrm{mv}$; temperature, $85^{\circ} \mathrm{C}$; times for running, $10^{6}$ )

\begin{tabular}{|c|c|c|c|c|c|}
\hline \multirow{2}{*}{$\begin{array}{c}\text { Alloys of contact and } \\
\text { spring leaf }\end{array}$} & & \multicolumn{2}{|c|}{ Before test (set limit value $100 \mathrm{~m} \Omega$ ) } & \multicolumn{2}{|c|}{$\begin{array}{l}\text { After test for running } 10^{6} \text { times } \\
\text { (set limit value } 500 \mathrm{~m} \Omega \text { ) }\end{array}$} \\
\hline & & Static & Dynamic & Static & Dynamic \\
\hline \multirow{5}{*}{ NSCGA gold alloy } & 1 & 60,58 & 62,64 & 54,53 & 49,52 \\
\hline & 2 & 62,58 & 59,59 & 55,57 & 48,47 \\
\hline & 3 & 57,58 & 60,63 & 50,51 & 49,51 \\
\hline & 4 & 56,56 & 62,65 & 56,62 & 48,50 \\
\hline & 5 & 61,60 & 62,65 & 56,61 & 48,50 \\
\hline \multirow{5}{*}{ SCPA palladium alloy } & 6 & 72,66 & 65,77 & 59,59 & 60,52 \\
\hline & 7 & 77,68 & 65,89 & 940,58 & 62,56 \\
\hline & 8 & 65,68 & 65,77 & 55,54 & 55,50 \\
\hline & 9 & 65,66 & 65,69 & $58, \infty$ & $\infty, \infty$ \\
\hline & 10 & 67,65 & 69,74 & 67,66 & 59,56 \\
\hline
\end{tabular}

contacts was assessed as grade $W$. (The quality level of reliability for relays is divided generally five grades, the fifth grade, namely grade $\mathrm{W}$, is the highest quality level.)

\section{Surface Composition of Contacts of used TO-5 Type Mini Relays}

All the contacts and spring leaves of TO-5 mini relays for tests and applications in present work were gold-plated (NSCGA and SCPA alloys) with pure gold film of $2 \mu \mathrm{m}$ thickness in order to guarantee high reliability of the relays. The surface compositions of NSCGA and SCPA alloy contacts were determined by the electron probe micro-area analysis, examining the damage of the gold-plating film as well as the transfer and loss of metals on the surfaces of the contacts. Table 4 lists the compositions on the surfaces of NSCGA and SCPA alloy contacts and spring leaves after loading life tests under conditions of the electric level of $0.5 \mathrm{~A}$ and $28 \mathrm{~V}_{\mathrm{DC}}$ and temperature of $125^{\circ} \mathrm{C}$. For NSCGA alloy contacts, from the data in Table 4, the gold contents of the upper and lower contacts and intermediate spring leaves are in the range of 91-93 wt.\% Au, much higher than the 61 wt.\% Au of the original NSCCA alloy. This indicates that the gold-plated films at the surfaces of NSCGA alloy contacts are basically perfect and losses and transfer of gold are small and uniform. The quantity of copper, palladium, nickel and platinum is very small but that of rhodium is quite high on the surface layers of NSCGA alloy contacts and spring leaves. This means that there is a tendency for rhodium to concentrate at the surfaces of grains of the second phase under operating conditions because rhodium is distributed mainly in the platinum-rich second phase with high melting point. It is advantageous to reduce adhesion due to welding and loss of metals and to guarantee high reliability and long life. For SCPA alloy contacts, the gold-plated films on the surfaces of contacts and spring leaves mostly disappeared. The upper contact contained $100 \% \mathrm{Pd}$ and was covered by PdO film. The other components were not present at all on the surface of the upper contact. The surface films made of silver-rich Ag-Pd-Cu alloy and palladium-rich Pd-Cu-Ag alloy were formed on the lower contact and intermediate spring leaves, respectively. The components of gold and platinum in contacts and spring leaves made of original SCPA palladium alloy was not measured. The formation of a PdO film lead to higher contact resistance. The surface composition is the direct reasons for serious loss and transfer of metals and adhesion due to welding. Frequent faults of contacts and spring leaves of the SCPA alloy are also observed.

\section{Application of NSCGA Alloy as Contacts}

NSCGA gold alloy has been used in a series of TO-5 type sealed mini relays and other products as contacts and spring leaves with high reliability and has substituted for the traditional six-component palladium alloy (SCPA). Moreover, the NSCGA alloy/copper alloy composites were also used in TO- 5 type mini relays and other relays as contacts for saving the gold alloy and reducing cost.

\section{Conclusions}

A new alloy based on gold with multi-component alloying and second phase strengthening was designed and prepared. The gold alloy is composed of two phases from high temperature close to the melting point of the matrix 
Table 3 Experiments of loading life and climbing limits of TO-5 type mini relays made of NSCGA and SCPA alloys as contacts and spring leaves.

\begin{tabular}{|c|c|c|c|}
\hline \multirow{2}{*}{ Test items } & \multirow{2}{*}{ Test conditions } & \multicolumn{2}{|c|}{ Contact materials of TO-5 mini relays* } \\
\hline & & NSCGA alloy & SCPA alloy \\
\hline \multirow{2}{*}{$\begin{array}{l}\text { Loading life at } \\
\text { ambient } \\
\text { temperature of } \\
20^{\circ} \mathrm{C}\end{array}$} & $\begin{array}{l}0.5 \mathrm{~A}, 28 V_{D C} \text { (specified life } \\
10^{6} \text { times) }\end{array}$ & $\begin{array}{l}\text { Loading life reached above } 10^{6} \text { times, } \\
\text { no fault occurred, the quality of relays } \\
\text { qualified }\end{array}$ & $\begin{array}{l}\text { Loading life was } 10^{5} \text { times, one relay } \\
\text { occurred faults of } 9 \text { times }\end{array}$ \\
\hline & $1.0 \mathrm{~A}, 28 \mathrm{~V}_{D C}$ & $\begin{array}{l}\text { Quality of relays qualified at running } \\
10^{5} \text { times }\end{array}$ & \\
\hline \multirow{3}{*}{$\begin{array}{l}\text { Loading life at } \\
\text { high temperature } \\
\text { of } 125^{\circ} \mathrm{C}\end{array}$} & $\begin{array}{l}0.5 \mathrm{~A}, 28 V_{D C} \text { (specified life } \\
10^{6} \text { times) }\end{array}$ & $\begin{array}{l}\text { No fault was observed during running } \\
\text { above } 10^{6} \text { times, the contacts and } \\
\text { spring leaves were in good condition } \\
\text { with small metal transfer and clear } \\
\text { gaps between them }\end{array}$ & $\begin{array}{l}\text { Welding and serious metal loss } \\
\text { occurred at running } 9 \times 10^{5} \text { times } \\
\text { between contacts and spring leaves, } \\
\text { none reaching specified life of } 10^{6} \\
\text { times }\end{array}$ \\
\hline & $1.0 \mathrm{~A}, 28 \mathrm{~V}_{D C}$ & $\begin{array}{l}\text { Contacts and spring leaves were in } \\
\text { good condition with small metal } \\
\text { transfer after running } 10^{5} \text { times }\end{array}$ & $\begin{array}{l}\text { Welding and serious metal transfer } \\
\text { and loss were occurred between } \\
\text { contacts and spring leaves }\end{array}$ \\
\hline & $100 \mathrm{~mA}, 28 V_{D C}$ & $\begin{array}{l}\text { No fault was observed at running } \\
5 \times 10^{4} \text { times in the test at temp. of } \\
125^{\circ} \mathrm{C}\end{array}$ & $\begin{array}{l}\text { All tested relays lost efficiency even in } \\
\text { the test at temp. of } 85^{\circ} \mathrm{C}\end{array}$ \\
\hline Vibration test & Vibrating acceleration & $\begin{array}{l}\text { Test was qualified by } 10 \mu \text { s supervising } \\
\text { under the conditions of } 10-2000 \mathrm{~Hz} \\
\text { frequency, } 196 \mathrm{~m} / \mathrm{s}^{2} \text { acceleration and } \\
20 \mathrm{~g} \text { loading }\end{array}$ & $\begin{array}{l}\text { Test was qualified by } 10 \mu \text { s supervising } \\
\text { under the conditions of } 10-2000 \mathrm{~Hz} \\
\text { frequency, } 147 \mathrm{~m} / \mathrm{s}^{2} \text { acceleration and } \\
15 \mathrm{~g} \text { loading }\end{array}$ \\
\hline Mechanical life & At ambient temperature. & $\begin{array}{l}\text { Mechanical life reached } 10^{8} \text { times, } \\
\text { various parameters and qualities } \\
\text { indexes kept stable }\end{array}$ & $\begin{array}{l}\text { Contact resistance was as high as } \\
1300 \mathrm{~m} \Omega \text { at running } 10^{6} \text { times, relays } \\
\text { lost efficiency }\end{array}$ \\
\hline $\begin{array}{l}\text { Operating at high } \\
\text { and low temp. }\end{array}$ & $\begin{array}{l}\text { Running } 3000 \text { times at } \\
125^{\circ} \mathrm{C} \text { for } 1 \mathrm{~h} \text {. Followed by } \\
\text { running } 3000 \text { times at } \\
-55^{\circ} \mathrm{C} \text { for } 1 \mathrm{~h} \text {. }\end{array}$ & $\begin{array}{l}\text { No fault was observed for } \\
18 \text { relays }\end{array}$ & $\begin{array}{l}\text { During operating process at high } \\
\text { temp. }\left(85^{\circ} \mathrm{C}\right) \text { and low temp. }\left(-55^{\circ} \mathrm{C}\right) \text {, } \\
20-30 \% \text { relays were not qualified. }\end{array}$ \\
\hline $\begin{array}{l}\text { Quality level of } \\
\text { reliability }\end{array}$ & $\begin{array}{l}\text { Environment temperature: } \\
-65-125^{\circ} \mathrm{C}\end{array}$ & Grade W & \\
\hline
\end{tabular}

* The fabrication and applications of all TO-5 type sealed mini relay were finished in a special relay factory

phase to the ambient temperature. The matrix phase is a solid solution $\mathrm{Au}(\mathrm{Cu}, \mathrm{Pd}, \mathrm{Ni})$ based on gold with the lattice parameter $\mathrm{a}_{1}=0.3905 \mathrm{~nm}$ and layer structure. The lattice parameter keeps essentially constant but the spacing between layers increases lightly in the aging process at low temperature. The second phase is a platinum-rich solid solution $\mathrm{Pt}(\mathrm{Au}, \mathrm{Rh}, \mathrm{Cu}, \mathrm{Ni})$ with lattice parameter $\mathrm{a}_{2}=0.3775 \mathrm{~nm}$. The particles of second phase are distributed in the layer structure, twins, on grain boundaries and dislocation lines of the matrix. This is responsible for the high strength and high wear resistance of the alloy. A short-range order with ordered structure $\mathrm{Au}_{3}(\mathrm{Cu}, \mathrm{Pd})$ and low grade ordering occurs in the range of $200-900^{\circ} \mathrm{C}$, leading to a decrease in the specific resistance and an increase of strength of the alloy. A modulated structure with composition modulation wavelength $\lambda=9 \mathrm{~nm}$ occurred in the aged state at low temperature and disappeared in the annealed state at $850^{\circ} \mathrm{C}$, contributing to age strengthening at the lower temperature.

The new six-component gold alloy (NSCGA) has low electric resitivity and temperature coefficient of resistance, high strength and hardness. The various TO-5 type sealed mini relays were prepared by a special relay factory and used for industrial application tests. The static and dynamic contact resistance remained stable and small, and no fault occurred during $10^{6}$ operations at low electric level of $50 \mu \mathrm{A}$ 
Table 4 The Surface Compositions on the Contacts and Spring Leaves made of gold-plating NSCGA and SCPA alloy after loading life tests at temperature of $125^{\circ} \mathrm{C}$ and $0.5 \mathrm{~A}$ and $28 \mathrm{~V}_{D C}$.

\begin{tabular}{|c|c|c|}
\hline \multirow{2}{*}{$\begin{array}{l}\text { Locations of } \\
\text { contacts and } \\
\text { spring leaf }\end{array}$} & \multicolumn{2}{|c|}{$\begin{array}{l}\text { Contents of components on the } \\
\text { surfaces of contact materials wt.\% }\end{array}$} \\
\hline & NSCGA alloy & SCPA alloy \\
\hline Upper contact & $\begin{array}{c}\text { Au:93.35,Cu:0.95, } \\
\text { Pd:1.67,Pt:0.00, } \\
\text { Ni: 0.60, Rh:3.42 }\end{array}$ & $\begin{array}{l}\text { Pd:100, (gold-plating } \\
\text { film disappeared) }\end{array}$ \\
\hline $\begin{array}{l}\text { Intermediate } \\
\text { spring leaf }\end{array}$ & $\begin{array}{c}\text { Au:91.23,Cu:1.41, } \\
\text { Pd:1.57,Pt:1.61, } \\
\text { Ni: 0.77, Rh:3.40 }\end{array}$ & $\begin{array}{c}\text { Pd:54.00,Ag:16.43, } \\
\text { Cu:29.56 (gold- } \\
\text { plating film } \\
\text { disappeared) }\end{array}$ \\
\hline Below contact & $\begin{array}{c}\text { Au:91.38,Cu:0.94, } \\
\text { Pd:2.02,Pt:1.65, } \\
\text { Ni: 0.6, Rh:3.40 }\end{array}$ & $\begin{array}{c}\text { Pd:39.86,Ag:41.57, } \\
\text { Cu:18.57 (gold- } \\
\text { plating film } \\
\text { disappeared) }\end{array}$ \\
\hline
\end{tabular}

and $30 \mathrm{mV}$. The various loading life at different electric levels and temperatures from $20^{\circ} \mathrm{C}$ to $125^{\circ} \mathrm{C}$ reached above $10^{6}$ times, an order of magnitude higher than the originally specified life set for TO-5 type mini relays with SCPA palladium alloy contacts. The quality level of reliability of the TO-5 type sealed mini relays with NSCGA alloy contacts and spring leaves was assessed as grade $W$, which is the highest quality level, at the environment temperatures from $-65^{\circ} \mathrm{C}$ to $125^{\circ} \mathrm{C}$. The NSCGA gold alloy has been used in TO- 5 type and other mini relays. This has been used as a contact with high reliability and has been substituted for the conventional sixcomponent palladium alloy with composition of Pd-30Ag14Cu-10Pt-10Au-1Zn.

\section{About the Author}

Professor Yuantao Ning is a Research Fellow at the Kunming Precious Metals Institute in China, working on a variety of research projects related to alloying principles and new materials based on precious metals. He has gained considerable scientific achievements and published about two hundred papers in international and domestic academic periodicals. He has been awarded national prizes for his achievements in scientific research. His work has also been concerned with research into applications for gold and its alloys.

Mrs Ying Peng is a senior engineer in QY radio factory. She has been engaged in design, fabrication and testing of radio components and relays. She has been awarded national prizes for her research achievements

Mrs Hong Dai is a senior engineer in Kunming Institute of Precious Metals for research of new materials based on precious metals. She has published several papers and has been awarded national prizes.

\section{References}

1 E.M. Wise, 'Gold Recovery, Properties and Applications', D. Van Nostrand Company Inc., Princeton, 1964

2 N. Harmsen, IEEE Trans. Components, Hybrids, and Manuf. Technol., 1978 V. CHMT-1(1), 79

3 T. Sakamoto, Z. Henmi and Y. Matsui, J. Japan Institute of Metals, 1965, 29(4), 382.

4 K.A. Gsehneidner Jr and F.W. Calderwood, Bull. Alloy Phase Diagrams, 1984, 5(4), 384

5 S. Zhang and Y. Yu, Precious Metals, 1983, 4(3), 15

6 F. Hofer and P.Z. Warbichler, Z. Metallkd., 1985, 76(1), 11

7 G. Kralik, Z. Metallkd., 1970, 61(10), 751 